\title{
Evaluation of a Training of Trainers Program on Food Safety and Nutrition Security
}

\author{
Alvyn Klein A. Mana-ay \\ Silliman University, Dumaguete City, Philippines \\ alvynamana-ay@su.edu.ph \\ https://orcid.org/0000-0002-9385-9572
}

\begin{abstract}
Foodborne diseases (FBDs) remain a serious human health problem, and food safety plays an essential role in addressing this public health issue. This study aimed at evaluating the training of trainers program on food safety and nutrition security using a qualitative descriptive approach. The training exposed the participants to food safety topics in food processing and preservation with an emphasis on the nature of food safety hazards and the personal hygiene of food handlers in food preparation. The new trainers then organized and conducted actual seminar-workshops in their respective communities. The results of the evaluation indicate that the primary driver of the success of the program was institutional support by the local government partners. Overall, the program was able to achieve its ultimate goal of capacitating a group of local trainers on food safety in hopes of addressing the problem of FBDs through a cascade of training.
\end{abstract}

Keywords: Food Safety, Foodborne Diseases, Training of Trainers, Qualitative-Descriptive, Negros Oriental, Philippines

Date Submitted: January 30, 2020

Date Revised: June 2, 2020

Date Accepted: June 15, 2020

\subsection{Introduction}

Many people understand that food must be nutritious and safe, but they often overlook food safety, a "hidden" characteristic of quality food (Chan, 2014). However, even when "millions of words" have been written on food safety, including the spending of considerable sums of money for it, the number of foodborne diseases (FBD) has not gone down considerably (Griffith \& Redmond, 2014). More often than not, it takes a food safety scandal to cause a more collective consciousness on the issue, albeit only for a while, as the threat of foodborne diseases is mostly forgotten until the next scandal (Chan, 2014). Recent examples of such scandals include the 2006 outbreak of Escherichia coli involving lettuce used in Taco Bell's products in the United States, the 2008 melamine-contaminated milk formula by Chinese manufacturer Sanlu, and the 2015 Caraga candy poisoning which affected more than 1,600 school children in the Philippines (Barbarossa, De Pelsmacker, Moons, \& Marcati, 2016). 
Ensuring the safety of food for consumption, an essential component to human survival remains a challenge due to hazards from microbiological, chemical, or physical agents (Ruby, Abidin, Lihan, Jambari, \& Radu, 2019). FBDs are significant health problems (Stedefeldt, Zanin, da Cunha, de Rosso, Capriles, \& de Freitas Saccol, 2015) in both developed and developing countries (Soares, Garcia-Diez, Esteves, Oliveira, \& Saraiva, 2013). FBD's global burden is estimated to affect one in every ten individuals, comparable to major infectious diseases such as HIV/AIDS, malaria, and tuberculosis (Gruenfeldova, Domijan, \& Walsh, 2019). The World Health Organization in its publication entitled "WHO Estimates of the Global Burden of Foodborne Disease" reports that 31 foodborne hazards are implicated in around 600 million foodborne illnesses worldwide with as much as $40 \%$ afflicting children under five years old (World Health Organization [WHO], 2015a). In the Philippines, a recent study by Azanza, Membrebe, Sanchez, Estilo, Dollete, Feliciano, and Garcia (2019) indicated a total number of 13,577 morbidity cases from the 209 documented outbreaks between the years 2005 to 2018 . The same study also showed microbiological and chemical toxins as causative agents associated with more than 90 of the recorded mortality cases for the same period. However, both indicators may underestimate the actual numbers due to problems related to access to and availability of information (Azanza et al., 2019).

The disease burden of FBD can also be costly because of its severe economic losses as a consequence (Nieto-Montenegro, Brown, \& LaBorde, 2008) as well as the harming of a country's development and foreign trade (Medeiros, Cavalli, Salay, \& Proença, 2011). In the United States alone, an estimated USD 14.0 billion annually is lost to medical costs, productivity losses, and valuation of premature deaths due to FBD, clearly demonstrating its negative economic impact (Stedefeldt et al., 2015).

Addressing FBD requires food safety, which, along with food security and healthy nutrition, is a crucial aspect of food systems important to human health (Walls, Baker, Chirwa, \& Hawkins, 2019). The Food and Agriculture Organization of the United Nations defines food security as "a situation that exists when all people at all times have physical, social, and economic access to sufficient, safe and nutritious food to meet dietary needs and food preferences for an active and healthy life" (FAO, 1996, cited in Walls et al., 2019, p. 69). This definition profoundly indicates the role of food safety in food security. Furthermore, the World Health Assembly made an abundantly clear statement on the relationship between food safety and nutrition security, citing that it is "Mindful of the inextricable links between food safety, nutrition, and food security, and acknowledging the instrumental role of food safety in eradicating hunger and malnutrition, in particular in low-income and food-deficit countries" (WHO, 2010, p. 6).

Evidence suggests that improper food handling is the principal cause of FBD outbreaks globally and are often associated with inadequate or inappropriate food safety practices by food handlers (da Cunha, Stedefeldt, \& de Rosso, 2014; Medeiros et al., 2011; Nieto-Montenegro et al., 2008; Ruby et al., 2019). Da Cunha et al. (2014) further state that professionals handling food may be responsible for up to $97 \%$ of reported FBD outbreaks. Additionally, non-professional food handlers may also be responsible if they disregard food safety guidelines and practices in domestic kitchens (Griffith \& Redmond, 2014). Behaviors that are frequently associated with FBD outbreaks include 
insufficient hand hygiene practices, inadequate maintenance cleaning of utensils and equipment, and unsatisfactory cooking and holding temperatures, and frequently occurs during the pre-preparation, preparation, and distribution of meals (da Cunha et al., 2014; Nieto-Montenegro et al., 2008). Ruby et al. (2019) reported several studies that demonstrated that consumer knowledge of food safety measures performs an indispensable role in decreasing the danger of FBD at home. Consequently, preventing FBD requires the training of food handlers of the basics of food hygiene to ensure safe food handling practices (WHO, 2013).

However, addressing the problem of FBD through food safety training may be difficult. Mormina and Pinder (2018) mentioned that shortages of trained health workers might pose a significant problem for developing nations in capacity building. The authors further point out that limited access to training, among others, contribute to public health workforce imbalances and may lead to poor health outcomes (Mormina \& Pinder, 2018). One of the methods to address this issue is the Training of Trainers (ToT) approach. Described by Baron (2006) as an approach that initiates "a cascade of training," the ToT forms a cascade as a new group of trainers' capacity is raised enough for them to inform the next group in an exponential sharing of information. The idea is focused on what Mormina and Pinder (2018) call the "up-skilling" through local trainers. Although there are many studies on food safety and other food hygiene education programs (da Cunha, Stedefeldt, \& de Rosso, 2014; Gruenfeldova, Domijan, \& Walsh, 2019; Medeiros et al., 2011; Nieto-Montenegro et al., 2008; Soares et al., 2013), studies looking into the impact of a ToT approach on food safety remain to be limited, especially in the context of community-based implementation.

In 2017, the HE-Nutrition and Dietetics Department (HEND) of Silliman University in the Philippines developed the "Nutrition and Food Security Training Program (NFSTP) in Selected Municipalities in Negros Oriental." The NFSTP was designed as a ToT program meant to train a pool of local trainers in the municipalities of Amlan and San Jose in the Province of Negros Oriental. A major component of the NFSTP, entitled "Food Safety and Food Processing and Preservation" is focused on food safety in food processing and preservation with an emphasis on the nature of food safety hazards as well as the personal hygiene of food handlers in food preparation which was an emerging issue in food contamination.

The NFSTP was developed following the successful run of its predecessor program entitled Indigenous Food Security for High-Risk Calamity Areas in Dumaguete City and Tacloban City: Silliman University Nutrition Intervention (Aclaro-Naranjo, Mana-ay, Honculada-Genove, \& Entea, 2018). With the local governments (LGU) of the municipalities of Amlan and San Jose in Negros Oriental as partners, the project was aimed at capacitating a group of local trainers on nutrition and food security interventions.

This paper aimed to evaluate the implementation of the ToT program of the HEND Department in terms of content delivery methods in the conduct of the training on the food safety and food processing and preservation module and the training capabilities of new trainers by the core facilitators during the field practice after the training sessions. The findings are meant to provide some basis for the improvement in the implementation of future ToT programs. It is also intended to offer guidance 
to implementing partners such as the LGUs in the conduct of food safety training in their localities.

\subsection{Methods}

The qualitative-descriptive approach, regarded as the research design used to provide a more straightforward description of the topic or phenomenon (Lambert \& Lambert, 2012), was used in this study.

The program followed a series of phases, namely, pre-implementation, implementation, and post-implementation. The pre-implementation phase was focused mainly on designing the program and the development of the training manual. The trainers' training manual was developed by four senior faculty members of the HEND Department which comprised of four modules covering the following topics: 1) nutrition in emergencies, 2) backyard gardening and home food production, 3) food safety and food processing and preservation, and 4) return demonstration and focus group discussion. Also conducted during this phase were the several meetings with the then prospective LGU partners that eventually led to the partnership agreement.

Part of the agreement reached during the pre-implementation phase was for the partner LGUs to identify the twenty ToT participants from their constituencies who were willing to be trained and willing to train others. The selected participants from the Municipality of San Jose were all local leaders. At that time, they were serving as either barangay chairpersons (captain), barangay councilors (kagawad), and barangay health workers. Those who were identified by the Amlan LGU were staff members of the various offices (e.g., social welfare and development, agriculture, disaster risk reduction, and management) as well as barangay officials, a local school principal, and teachers. All of the participants are widely seen as people with high standing in their respective communities due to their positions at the time of selection.

The implementation phase was the actual conduct of the ToT covering the four modules of the program. The actual training was conducted in venues provided by the partner LGUs in their municipalities except for module 3, which was held at the HEND Department. A total of four full-day training workshops were conducted for each of the two groups of participants. Each training was facilitated by a senior faculty who served as the primary resource person and was assisted by two junior faculty members, a nonteaching staff, and some student-volunteers.

The last phase, post-implementation, served as the last leg of the program and covered six months following the trainers' training. A significant activity of this phase was the actual conduct of seminar-workshops facilitated by the trained participants during the second phase. As a requirement, the field practice was evaluated by the HEND faculty members.

Both content and delivery methods of module 3 were examined and compared against some of the widely accepted practices found in the literature. As for the evaluation of the field practice, an evaluation guide was used by the senior faculty of the HEND Department, who also served as evaluators during the return demonstration. The new trainers were then evaluated according to their knowledge on the subject matter, ability to provide clear instructions and guidelines, being brief and concise, ability to handle difficult participants, ability to listen effectively to participants, ability 
to control group discussion, ability to involve all participants, ability to respond properly to queries, stimulating, interactive, and comprehensive during the discussion of topics, being effective and engaging resource persons/facilitators, being able to provide appropriate and interesting visual aids, being able to build cooperation, being helpful, and ability to solicit feedback.

At the end of the field practice, a focus-group discussion (FDG) was conducted with a senior faculty serving as a moderator. A set of questions was used as a guide during the FDG sessions. The FGD was intended to draw out relevant information from the new trainers on areas for improvement in the conduct of future training.

Analysis, as in qualitative-descriptive studies, was done by obtaining a more general sense of the participants' feelings and responses as well as from the records of observations by the faculty-evaluators.

\subsection{Results and Discussion}

\section{Content Delivery of the Training of Trainers}

The training which covered the third module of the program, as described in the previous section, was conducted at the HEND Department. Participants from the two municipalities were brought to the Silliman University campus in Dumaguete City. Module 3 consisted of two main topic sessions: 1) food safety, and 2) food processing and preservation. Table 1 highlights the specific topic contents of each session, including the learning strategies employed for each topic. Fundamental learning principles under the first session were integrated into the topics of session 2 to underline the importance of food safety in food preservation and processing.

Table 1. Topics on the Food Safety and Food Processing and Preservation Module

\begin{tabular}{|c|c|c|}
\hline Session & Topic & Learning Strategy \\
\hline \multirow{5}{*}{ Food Safety } & Introduction to Food Safety & Lecture-discussion \\
\hline & Food Safety Hazards & $\begin{array}{l}\text { Group Activity } \\
\text { Lecture-discussion }\end{array}$ \\
\hline & $\begin{array}{l}\text { Cross-contamination and Personal } \\
\text { Hygiene }\end{array}$ & $\begin{array}{l}\text { Storytelling } \\
\text { Group Activity } \\
\text { Lecture-discussion }\end{array}$ \\
\hline & WHO's Five Keys to Safer Food & $\begin{array}{l}\text { Video Presentation } \\
\text { Lecture-discussion }\end{array}$ \\
\hline & Proper Hand-washing Procedure & $\begin{array}{l}\text { Lecture-discussion } \\
\text { Demonstration }\end{array}$ \\
\hline \multirow{5}{*}{$\begin{array}{l}\text { Food } \\
\text { Processing } \\
\text { and } \\
\text { Preservation }\end{array}$} & $\begin{array}{l}\text { Introduction to Food Processing and } \\
\text { Preservation }\end{array}$ & $\begin{array}{l}\text { Group Activity } \\
\text { Lecture-discussion }\end{array}$ \\
\hline & Facts About Food Losses & Lecture-discussion \\
\hline & Causes of Food Deterioration & Lecture-discussion \\
\hline & Methods of Food Processing & Lecture-discussion \\
\hline & $\begin{array}{l}\text { Preparation of the Emergency Food } \\
\text { Reserve }\end{array}$ & $\begin{array}{l}\text { Lecture-discussion } \\
\text { Return-demonstration }\end{array}$ \\
\hline
\end{tabular}


Several training strategies were employed to ensure more participant-centered learning. Topics that used the lecture-discussion strategy were complemented with PowerPoint ${ }^{\circledR}$ presentations to enhance the participants' learning experience. The topic of cross-contamination used the storytelling technique. It emphasized the significance of personal hygiene on the prevention of cross-contamination using the story of Mary Mallon. She was responsible for a series of Salmonella outbreaks in the U.S. in the early 1900s, which eventually earned her the moniker "Typhoid Mary" (Marineli, Tsoucalas, Karamanou, \& Androutsos, 2013).

Another interesting strategy used is the audio-visual presentation of WHO's Five Keys to Safer Food (WHO, 2006). The video, developed by the World Health Organization, was used to introduce the participants to WHO's simpler and generally accepted set of guidelines to educate food handlers in the home and commercial kitchens of their responsibilities for food safety. It consisted of the following five (5) core messages: (1) keep clean, (2) separate raw and cooked, (3) cook thoroughly, (4) keep food at safe temperatures, and (5) use safe water and raw materials (WHO, 2006). An instructor-led demonstration was used to present the hand-washing procedure adapted from Kozier, Erb, Blais, Johnson, and Temple (1993). It underscored hand-washing as the most important and most basic technique in preventing the transmission of pathogens. After that, the participants were asked to individually return-demonstrate the entire procedure.

Contents of session two topics were similarly delivered as the topics in session one primarily using the lecture-discussion and group learning activity methods. However, the bulk of the time for this session was spent on the last topic on the preparation of emergency food reserve. This was done through guided food preparation of food items, which can be stored longer without the need for specialized food storage equipment (e.g., freezer, refrigerator). Throughout the food preparation activity, food safety principles were incorporated and emphasized. Before the participants were allowed to begin, they were all required to put on their protective equipment (i.e., hair net, face mask, apron/lab gown). They were also obliged to cleanse their hands following the prescribed hand-washing procedure thoroughly. They were also constantly reminded to wash their hands in between tasks and after completing assigned tasks.

All of the recipes used in the activity also focused on the destruction of potential FBD agents and the avoidance of recontamination. Techniques in food preservation highlighted in the activity were thermal processing (frying and boiling), drying, and home canning method. The participants were also introduced to the SAGIP powder and how it is prepared. SAGIP, a ready reserve food item that is meant to help the community and its members prepare during calamities, is a project spearheaded by the Food Processing Division of the Industrial Development Institute of the Department of Science and Technology (Montevirgen, 2010). Cassava, mung beans, malunggay, sweet potato, or saba banana are some examples of fresh produce that may be processed to make the SAGIP powder stored and used to correct problems of malnutrition in the community brought about by disasters and calamities.

The NFSTP's modules were all designed to deliver its content using learnercentered strategies to enhance the learning experience of the participants. For instance, various training strategies such as lecture-discussions, audio-visual 
presentations, group activities, and demonstrations were employed in Module 3's Food Safety and Food Processing and Preservation. Using such strategies in the conduct of food safety training is transformative and can change food handling practices (da Cunha et al., 2014).

The lecture-discussion method was supported with structured notes using PowerPoint ${ }^{\circledR}$ presentations and was used to guide the discussion component. Lectures paired with structured group discussions are deemed a useful teaching strategy (Johnson \& Mighten, 2005). The use of storytelling, also known as narrative pedagogy, in the delivery of the content under the cross-contamination topic is also worthy of note since the strategy is widely viewed to allow the learners to gain a deeper understanding of the topic through the interpretation and reflection on the stories (Cangelosi \& Whitt, 2006). Another useful teaching strategy is the use of audio-visual presentation using WHO's Five Keys to Safer Food video (WHO, 2015b). The video was used to complement the discussion on WHO's key recommendations to the public on the ways to keep food safe for consumption using an animated movie that is not only catchy and humorous but also appropriate for all ages (Fontannaz-Aujoulat, Frost, \& Schlundt, 2019).

Building on the knowledge gained in the previous topic, the section on hand-washing was conducted through an instructor-led demonstration to stress the importance of hand hygiene to reduce cross-contamination. This part of the training was crucial because it is intended for the participants to learn the correct hand-washing steps and show them how it is to be taught to others. Soares et al. (2013) reported several studies indicating that food handlers practiced hand disinfection rigorously after being taught the correct hand-washing procedure during food safety training.

\section{Training Capabilities of New Trainers}

As earlier mentioned, the participants were required to organize a seminarworkshop as part of the training evaluation. Prior to this, they underwent mock-up sessions on how to successfully conduct their training, which was part of the activities of Module 4. In the months following their completion of the four modules, the participants were then asked to organize and conduct a seminar-workshop in their locality. They were asked to choose two modules in the training manual to use as topics. The trainers themselves chose their respective teams and topics, and in accordance with the suggestions made by their respective local government heads. In the end, three teams were organized for the field practice. Of the three, one group chose module 3 as part of their training topics. This group, hereafter referred to as Team 2, is one of the two groups of the Municipality of San Jose.

The seminar-workshop organized and facilitated by Team 2 was held at the Tapon Norte Elementary School located in Barangay Tapon Norte. The training site was selected because many, if not most, of the team members, were residents and local leaders in the area. A total of 26 participants joined the whole-day activity mostly by mothers, barangay health workers, and officials of the Tapon Norte's barangay LGU and from neighboring barangays. Following the prescribed format in the conduct of the training, the team spent the morning on the contents of the session on food safety and then on the contents of the session on food processing and preservation in the afternoon. 
Team 2 was evaluated by the core training facilitators composed of the senior faculty members of the HEND Department. After the training, a debriefing session was conducted with Team 2 that was meant to highlight the team's strengths as well as review the areas for improvement. Individual responses generated during the debriefing session from the team members were also recorded as part of the documentation process.

\section{Evaluation of Return Demonstration of Trainers}

Results of the evaluation conducted by the senior faculty showed that the new trainers were able to successfully deliver a training-workshop with an overall rating of "very good." The evaluation team noted that the trainers were able to follow the recommended format prescribed in the manual, including the conduct of a pre/ post-test, demonstration, and return demonstration of key sessions of module 3 . The facilitators were also able to gain the attention of the participants who, in turn, were very cooperative and responsive, which made the activity more meaningful. The evaluators also agreed that the trainers' competencies relative to their ability to solicit feedback, handle difficult participants, listen to participants' responses, and generally being helpful are "excellent." This suggests that while they are relatively new and may have difficulty in the delivery of some of the contents in the learning material, they were trying to engage their participants as much as possible. Additionally, the trainers remarked during the debriefing session that while they were initially concerned as to how they would respond to potential prejudices on food safety practices among their participants, they felt that they were able to overcome them by providing specific examples of what might happen if food safety practices are ignored.

Furthermore, the evaluators cited the trainers' capability in integrating their personal experiences in their discussions as one of the positive highlights of the training they conducted. The trainers expressed that conveying their interpretations and personal experiences allowed them to be more confident in delivering the content, suggesting that they could internalize the key messages of the topics they handled. This is an important finding, as learning is more impactful when the learner can nurture deeper connections with the learning material (Lefkowich, Richardson, Brennan, Lambe, \& Carroll, 2016). The trainers further added that organizing a seminar-workshop, a key requirement for them to complete their training, meant that they had to see themselves as knowledge providers and that this required a level of knowledge enough to raise their confidence as trainers.

\section{Evaluation of the Training Environment}

Several other positive comments made by the evaluating team include the training venue which was well furnished (adequate number of chairs, tables, writing board, fans, appropriate lighting) and the thoughtful provision of snack items by the facilitating team which was shared and enjoyed by all following the end of the activity. It is also worth mentioning the extraordinary support extended by the LGU to the training organized by the new trainers. Not only were the local leadership cooperative, but they were also more than willing to provide logistical and financial support, particularly in 
the provision of the training venue, transportation arrangements, and making available some funding for food. The LGUs also extended other forms of assistance, such as allowing their members to attend the training while on leave of absence with pay. The LGU's support to this endeavor can be considered as one of the most important drivers that eventually led to the success of the project, given that a lack of favorable institutional environment is seen as a significant barrier to food safety compliance (Rincon-Ballesteros, Lannelongue, \& González-Benito, 2019).

While the new trainers were able to achieve the objectives of the training overall, more can be done in terms of their level of preparedness on the subject matter. Preparedness must be extensive relative to their basic understanding and knowledge of the contents of the module as well as the prescribed learning strategies employed. The trainers believed that preparations can still be improved in terms of comprehensively reviewing the training manual and understanding the learning strategies to ensure that participants get the most out of the activity. In addition, the facilitators were also acutely aware of the need to render the contents more appropriate for some participants who found some of the more technical terms difficult to understand.

Other items that were pointed out during the debriefing session were on the return demonstration equipment, appropriateness of visual aids used as well as the training venue. The evaluation team observed that some personal protective equipment such as hairnet and aprons were missing in some of the participants. The visual aids used were also small in size, making them difficult to be seen by the participants at the back. The venue was well appreciated for its use; it was warm, accounting to the summer heat, and may not have made the overall environment conducive to learning.

\subsection{Conclusion}

The FBDs remain an important public health problem and a significant threat to economies of both the developed and developing worlds. As the relationship between food safety and food and nutrition security is undeniable, addressing FBDs through food safety measures is essential to achieve a healthy population. One such measure is the training of food handlers both in the home and in commercial kitchens. However, this may be difficult as there exists a scarcity of trained health professionals to lead such training. An approach to this problem is the upskilling of food safety knowledge using the ToT model.

The food safety ToT of the Nutrition and Food Security Training Program of Silliman University was implemented in partnership with selected local governments in Negros Oriental. The contents of the program's training manual were delivered using some of the widely accepted and generally effective learner-centered strategies such as lecture-discussions, audio-visual presentations, and demonstrations.

Results of the field practice evaluation showed a generally positive outcome suggesting that the program was able to achieve its ultimate goal of capacitating a group of local trainers on food safety in hopes of addressing the problem of FBDs through a cascade of training. Additionally, it was observed that institutional support by the partner LGUs was critical to the success of the program.

However, in order for the partner LGUs to maximize the potential use of the program, it is recommended that an evaluation of both the practices on food safety by 
the trained food handlers and the safety of their products be conducted. Furthermore, given the importance of institutional support as a key driver for success described in this paper, partner LGUs are advised to revisit their roles in the implementation of food safety programs and the regulation of food handling activities in their respective communities. Finally, it is recommended that further training and workshops on food safety measures be implemented to ensure that food safety knowledge is transformed into practice and thereby prevent the outbreak of FBDs.

\subsection{Acknowledgment}

The author thanks the active participation of the ToT trainers as well as the generous support and involvement of their respective LGUs. Special thanks to the Office of the Vice President for Development of Silliman University for the funds provided in the implementation of the project. Worthy of recognition is the support and assistance in the development of this paper by Dr. Enrique G. Oracion, the Director for Research at Silliman University.

\section{REFERENCES}

Aclaro-Naranjo, M., Mana-ay, A. K. A., Honculada-Genove, J., \& Entea, R. A. S. (2018). Nutrition Intervention as Service Learning: Silliman University's Indigenous Food Security in Philippine High-Risk Calamity Areas. In SHS Web of Conferences (Vol. 59, p. 01020). EDP Sciences.

Azanza, M. P. V., Membrebe, B. N. Q., Sanchez, R. G. R., Estilo, E. E. C., Dollete, U. G. M., Feliciano, R. J., \& Garcia, N. K. A. (2019). Foodborne Disease Outbreaks in the Philippines (2005-2018). Philippine Journal of Science, 148(2), 317-336.

Barbarossa, C., De Pelsmacker, P., Moons, I., \& Marcati, A. (2016). The influence of country-of-origin stereotypes on consumer responses to food safety scandals: The case of the horsemeat adulteration. Food quality and preference, 53, 71-83.

Baron, N. (2006). The 'TOT': A Global Approach for the Training of Trainers for Psychosocial and Mental Health Interventions in Countries Affected by War, Violence, and Natural Disasters. National Emergency Training Center.

Cangelosi, P. R., \& Whitt, K. J. (2006). Teaching through storytelling: An exemplar. International Journal of Nursing Education Scholarship, 3 (1): 1-8.

Chan, M. (2014). Food safety must accompany food and nutrition security. The Lancet, 384(9958), $1910-1911$.

Da Cunha, D. T., Stedefeldt, E., \& de Rosso, V. V. (2014). The role of theoretical food safety training on Brazilian food handlers' knowledge, attitude, and practice. Food Control, 43: 167-174.

Fontannaz-Aujoulat, F., Frost, M., \& Schlundt, J. (2019). WHO Five Keys to Safer Food communication campaign-Evidence-based simple messages with a global impact. Food Control, 101: 53-57.

Griffith, C., \& Redmond, E. (2014). Risk analysis: food safety training and health education: principles and methods. Encyclopedia of Food Safety, 1: 142-151.

Gruenfeldova, J., Domijan, K., \& Walsh, C. (2019). A study of food safety knowledge, practice, and training among food handlers in Ireland. Food Control, 105, 131-140.

Johnson, J.P. \& Mighten, M. (2005). A comparison of teaching strategies: lecture notes combined with structured group discussion versus lecture only. Journal of Nursing Education, 44(7), 319.

Kozier, B., Erb, G., Blais, K., Johnson, J.Y., \& Temple, J.S. (1993). Techniques in clinical nursing. $4^{\text {th }}$ ed. Ca: Addison, Wesley.

Lambert, V. A., \& Lambert, C. E. (2012). Qualitative descriptive research: An acceptable design. Pacific Rim International Journal of Nursing Research, 16(4), 255-256.

Lefkowich, M., Richardson, N., Brennan, L., Lambe, B., \& Carroll, P. (2016). A process evaluation of a Training of Trainers (TOT) model of men's health training. Health Promotion International, 33(1), 60-70.

Marineli, F., Tsoucalas, G., Karamanou, M., \& Androutsos, G. (2013). Mary Mallon (1869-1938) and the history of typhoid fever. Annals of Gastroenterology: Quarterly Publication of the Hellenic Society of Gastroenterology, 26(2), 132. 
Medeiros, C. O., Cavalli, S. B., Salay, E., \& Proença, R. P. C. (2011). Assessment of the methodological strategies adopted by food safety training programs for food service workers: a systematic review. Food Control, 22(8), 1136-1144.

Montevirgen, L. S. (2010). Ang paggawa ng SAGIP para sa inyong communidad. Food Processing Division, Industrial Technology Development Institute, Department of Science and Technology. Taguig, Metro Manila.

Mormina, M., \& Pinder, S. (2018). A conceptual framework for the training of trainers (ToT) interventions in global health. Globalization and health, 14(1), 100.

Nieto-Montenegro, S., Brown, J. L., \& LaBorde, L. F. (2008). Development and assessment of pilot food safety educational materials and training strategies for Hispanic workers in the mushroom industry using the Health Action Model. Food Control, 19(6), 616-633.

Rincon-Ballesteros, L., Lannelongue, G., \& González-Benito, J. (2019). Implementation Of The Brc Food Safety Management System In Latin American Countries: Motivations And Barriers. Food Control, 106715: 1-9.

Ruby, G. E., Abidin, U. F. U. Z., Lihan, S., Jambari, N. N., \& Radu, S. (2019). A cross-sectional study of food safety knowledge among adult consumers. Food Control, 99: 98-105.

Soares, K., Garcia-Diez, J., Esteves, A., Oliveira, I., \& Saraiva, C. (2013). Evaluation of food safety training on hygienic conditions in food establishments. Food Control, 34(2), 613-618.

Stedefeldt, E., Zanin, L. M., da Cunha, D. T., de Rosso, V. V., Capriles, V. D., \& de Freitas Saccol, A. L. (2015). The role of training strategies in food safety performance: knowledge, behavior, and management. In Food Safety (pp. 365-394). Academic Press.

Walls, H., Baker, P., Chirwa, E., \& Hawkins, B. (2019). Food security, food safety \& healthy nutrition: are they compatible? Global Food Security, 21: 69-71.

WHO (World Health Organization). (2006). Five keys to safer food manual. WHO Department of Food Safety, Zoonoses, and Foodborne Diseases.

WHO (World Health Organization). (2010). Sixty-third World Health Assembly WHA63/2010/REC/1, Resolutions, and decisions 2010.

WHO (World Health Organization). (2013). Advancing food safety initiatives: strategic plan for food safety, including foodborne zoonoses 2013-2022.

WHO (World Health Organization). (2015a). WHO estimates of the global burden of foodborne diseases: foodborne disease burden epidemiology reference group 2007-2015 (No. 9789241565165). World Health Organization.

WHO (World Health Organization). (2015b). YouTube world health organization. Retrieved October 2019, from YouTube Five Keys to Safer Food video: https://www.youtube.com/watch?v=ONkKy68HEIM. 